\title{
The Effect of Age and Drought on the Recovery of Midday Leaf Hydraulics and Physiological Traits in Oat (Avena nuda)
}

\author{
Huma Batool $^{1,2}$, Sumaira Farrakh ${ }^{2}$ and Tayyaba Yasmin ${ }^{2 *}$ \\ ${ }^{1}$ Department of Botany, Sardar Bahadur Khan Women's University Quetta, Quetta Campus, 87300, Pakistan \\ ${ }^{2}$ Department of Biosciences, COMSATS University Islamabad, Islamabad Campus, 45550, Pakistan \\ *For Correspondence: tayyaba_yasmin@comsats.edu.pk; drtayyabayasmin@gmail.com \\ Received 15 September 2020; Accepted 29 November 2020; Published 25 January 2021
}

\begin{abstract}
The leaf hydraulic behavior has a significant role on species survival because plants often encounter drought. The effect of age and drought on the leaf water potential $\left(\Psi_{\mathrm{L}}\right)$, leaf hydraulic conductance $\left(\mathrm{K}_{\mathrm{L}}\right)$, stomatal density $(\mathrm{SD})$ and size $(\mathrm{SS})$, evapotranspiration $(\mathrm{E})$, net photosynthetic rate $(\mathrm{Pn})$ stomatal conductance $(\mathrm{gs})$ and their post drought recovery in naked oat is not understood. This study investigated these facts in two naked oat cultivars, Yanmai (Ym) and Dingyou7 (Dy7). The plants were grown in pots and kept well-watered (WW) for the first $\sim 30$ days after sowing (DAS) after that for Experiment 1) the plants were kept in a rainout shelter; in a growth room and kept WW throughout. Experiment 2) the plants were grown at $40 \%$ drought to determine the effect of drought on the SD and SS. Experiment 3) the plants were grown in 40\% field water capacity (FC) for 25 days then, they were recovered from drought stress and $\Psi_{\mathrm{L}}, \mathrm{K}_{\mathrm{L}}, \mathrm{SS}, \mathrm{SD}, \mathrm{E}, \mathrm{Pn}$, and gs were determined. Under the drought, Ym lost $\mathrm{K}_{\mathrm{L}}$ whereas; Dy7 could maintain $\mathrm{K}_{\mathrm{L}}$ and higher midday $\Psi_{\mathrm{L}}$ and lower SD than Ym. The cultivar Dy7 showed maximum recovery of $\mathrm{K}_{\mathrm{L}}, \Psi_{\mathrm{L}}, \mathrm{Pn}$, gs and $\mathrm{E}$ than $\mathrm{Ym}$ upon re-watering. The loss and recovery of $\mathrm{K}_{\mathrm{L}}, \Psi_{\mathrm{L}}, \mathrm{Pn}, \mathrm{E}$, gs and $\mathrm{SD}$ is controlled genetically in naked oat cultivars in combination with the environmental factors and the cultivar Dy7 has potential to enhance drought resistance in crops plants by genetic crop breeding. (C) 2021 Friends Science Publishers
\end{abstract}

Keywords: Avena nuda; Hydraulic; Evapotranspiration; Stomata; Recovery

\section{Introduction}

The survival and sustainability of land ecosystems depend on the hydraulic activities of plants by means of adaptation to the dryer environments as they shifted to land from water millions of years ago. The transpirational water pull is dependent upon physiological activities of plants such as leaf water potential $\left(\Psi_{\mathrm{L}}\right)$, hydraulic conductance $\left(\mathrm{K}_{\mathrm{L}}\right)$, and gas exchange through stomata that in turn is responsible for the net photosynthetic rate. The dependence of plants on water availability remains one of the major limitations in their lives, because they might face mild to severe droughts stress during any stage of their life. The seasonal herbaceous plants are typically more sensitive to the soil water status than the more resilient biannual or perennial woody plant species. About $99 \%$ of water required by the plants is utilized for transpiration to keep them cool and save them from wilting due to the heat of the sun (Bertolino et al. 2019). The midday $\Psi_{\mathrm{L}}$ is lost more rapidly than the predawn $\Psi_{\mathrm{L}}$ as the plant age, but under drought stress ultimately it reaches a threshold level at which the midday and predawn $\Psi_{\mathrm{L}}$ becomes equal, causing a total loss of leaf water potential (Meinzer et al. 2016). A complete loss of leaf hydraulic conductance results in the fatal leaf water potential that causes death of the leaf. The climate change has increased the global temperatures and drought events in different parts of the world (Gu et al. 2020). Consequently, high atmospheric temperature and drought have a negative impact on the midday $\Psi_{\mathrm{L}}$.

Different plant species generally behave similarly towards the water stress environments but variations exist between and within species levels and these differences are the source of species survival in the current era while water scarcity is expected to be greater than the past. The variations in interspecific hydraulic traits allow plants to display different phenological and photosynthetic responses to water stress (Mendez-Alonzo et al. 2013). Xylem, as a physical entity, is an important determining factor of hydraulic behaviors of different plants species. The plant communities in an ecosystem are dependent on the structure of xylem tissue for their ability to adapt to the changing soil water status that does not remain constant in a natural environment (Rosas et al. 2019). On the other hand, the structural resistance of leaf tissue outside xylem also has important influence on the hydraulic traits of a leaf for instance, the mutant tomato plants lacking bundle sheath extensions showed lower leaf hydraulic conductance,

To cite this paper: Farrakh HBS, T Yasmin (2021). The effect of age and drought on the recovery of midday leaf hydraulics and physiological traits in oat (Avena nuda). Intl J Agric Biol 25:581-590 
evapotranspiration and lower assimilation rates in comparison with the wild type plants growing in the same environmental conditions (Zsögön et al. 2015).

Xylem embolism may occur due to cavitation that is usually driven by a low water potential. The low water potential causes a loss of plant hydraulic conductivity due to which the plant cannot transport water from roots to the aerial portions of the plant (Venturas et al. 2017) including the leaves, where evapotranspiration demands more water in exchange to the $\mathrm{CO}_{2}$ required for the survival of the plants. Due to decreased available water in the soil the water potential of a plant $\Psi_{\mathrm{P}}$ declines, this causes a high water tension in the xylem that results in cavitation by expansion of air bubbles that are generally dissolved in the water. This air bubble trapped in the xylem, blocks tracheid, or vessels due to which the water cannot be transported through the xylem. The blockage of xylem vessel or tracheid with an air bubble is known as xylem embolism. A temporary loss of $\mathrm{K}_{\mathrm{p}}$ can be recovered by re-watering the plants whereas, the permanent loss of $K_{P}$ cannot be reversed with any level of watering. The extent of damage caused to water transport system is determined by many factors including the inherent differences in plant species and the environmental conditions, such as level and duration of a drought event.

Plants show species specific resistance to xylem embolism, but some studies have also focused the intraspecific variations of plants to adapt to the dryer environments (Cardoso et al. 2018). Besides the intraspecific differences of plant's ability to recover from xylem embolism, there may exist leaf-to-leaf differences that is not yet discovered and discussed for many plant species and requires to be explored in different plants (Rodriguez-Dominguez et al. 2018). Variation in the loss of hydraulic conductance because of low leaf water potential in different leaves is recently reported in the avocado tree species Persea americana (Cardoso et al. 2020). These kinds of variations may also be specific for a species and all the plant species may not exhibit such variations in loss of leaf hydraulic conductance amongst different genotypes of the same species such as, five different genotypes of four coffee species Coffea spp. have been recently reported to show similar resistance to the loss of leaf hydraulic characteristics (Mauri et al. 2020). The pit membrane structure has been of late recognized as an important source of similarities or differences in hydraulic traits of different plant species (Zhang et al. 2020). Complete hydraulic failure may occur in plants, where the water transport system of plants is impaired to such an extent that they cannot revive the normal hydraulic behaviors (Nardini et al. 2013). Besides these important advancements, many of the structural, genetic and environmental factors that determine the differences in hydraulic traits of different plant species are yet to be discovered.

Stomatal density is recognized as an important structural feature that may control the hydraulic behavior and water use efficiency of any plant (Lawson and Vialet-
Chabrand 2019). The number of stomata in the upper and lower epidermis of leaves is a part of the evolutionary process of plants and depends on genetic features of a plant. Some studies have shown the effects of abiotic environmental conditions such as the $\mathrm{CO}_{2}$ level in the atmosphere and water availability on the stomatal density and size per unit leaf area (Caine et al. 2019). The grass species have a dumbbell shaped guard cells and they are believed to be evolutionarily advanced plant species because of their guard cells shape and movements. Many crop plants such as tomatoes (Liu et al. 2015) and grass family cereals such as maize (Morales-Navarro et al. 2018) and barley (Hughes et al. 2017) have been genetically modified successfully by overexpression of Arabidopsis thaliana and barley genes that are responsible for reducing the stomatal density by $50 \%$. These plants show better water use efficiency (WUE) and enhanced yield than the control plants under drought conditions.

Few studies have so far discussed the leaf and whole plant hydraulic behaviors in relation to the age of herbaceous annual plants. In the natural environment place often face mild to severe drought. The factors determining the optimized physiological performance of plants under drought and post drought recovery have not been investigated for $A$. nuda. The effect of growing age of plant and drought stress on the leaf hydraulic conductance, stomatal density and midday leaf water potential is also never explored for naked oat. The purpose of this study was to explore the effect of age of the annual herbaceous plant (A. nuda) on $\Psi_{\mathrm{L}}, \mathrm{K}_{\mathrm{L}}, \mathrm{Pn}$, gs and $\mathrm{E}$ in the absence of any drought. The effect of drought on the stomatal density and size in upper and lower epidermis was also investigated for the A nuda L. cultivars. Similarly, the recovery of these physiological activities was also evaluated under different watering patterns after a temporary drought.

\section{Materials and Methods}

\section{Plant material}

The naked oat cultivars Yanmai (Ym) which is a $\sim 70$ years old indigenous Chinese cultivar and recently established Chinese cultivar Dingyou7 (Dy7) were used in this study. These cultivars were chosen for this study because these show contrasting sensitivities to drought stress (Wang et al. 2017). The seeds were generously supplied by the Institute of Crop Germplasm Resources from the Chinese Academy of Agricultural Sciences (Beijing, China) and the Dingxi Academy of Agricultural Science (Dingxi, Gansu, China).

\section{Experimental design and growth conditions}

The two naked oats were grown in $24 \mathrm{~cm}$ high and $23 \mathrm{~cm}$ wide pots in a rainout shelter to control the irrigation in a completely randomized design (CRD) (Fisher 1935, 1971). To minimize the effect of pot position the pots were 
reshuffled regularly throughout the duration of the experiments. The pots were filled with $7 \mathrm{~kg}$ topsoil and vermiculite mixture supplemented with ample nutrition in the form of potassium $(\mathrm{K})$, sodium $(\mathrm{N})$, and phosphorus $(\mathrm{P})$. The Field water capacity (FC) of this soil mixture was $\sim 37 \%$. Each pot was supplied with ample nutrition mainly comprising of Potassium (K), Nitrogen (N) and Phosphorus (P). The seeds were sown in pots in two growing seasons, on April 2, 2018 and June 1, 2018. The pots were inoculated with seven seeds per pot at a distance of $\sim 3$ inches from all sides, to avoid further thinning. The seedlings started to emerge after $72 \mathrm{~h}$. There were five replicate pots for each water treatment and the control plants (details given below).

\section{Field water capacity (FC)}

The soil was saturated with water until it became free running and extra water was allowed to drain for $72 \mathrm{~h}$. The weight of saturated soil sample was calculated by subtracting the weight of empty container. The wet soil was then dried in an oven at $105^{\circ} \mathrm{C}$ for 48 to $72 \mathrm{~h}$ and dry soil weight was noted. FC was calculated as the difference between weights of the saturated soil and the oven-dried soil (Ogbaga et al. 2014). The procedure was repeated thrice and mean values were calculated as the final FC.

\section{Water treatments}

Experiment 1: The plants were well watered for the first $\sim 30$ DAS, then a moderate to severe drought of $\sim 40 \% \mathrm{FC}$ that is often met by plants in the field conditions was applied for $\sim 25$ days. After that the plants were recovered from water stress by re-watering and three different watering schemes were applied (a) well-watered with $\sim 100 \%$ FC (b) water stressed plants having an FC of $\sim 50 \%$ and (c) no watering at all with complete drought allowing the soil to dry progressively during the experiment. The $\mathrm{K}_{\mathrm{L}}$, $\Psi_{\mathrm{L}}, \mathrm{Pn}, \mathrm{E}$ and gs were measured during the drought and after recovery in the three different water treatments as well as in the control (C) plants that were kept in well-watered (WW) conditions throughout the duration of the experiments. The FC was maintained by weighing the pots daily and adding the lost amount of water to the pots.

Experiment 2: The plants were kept well watered (WW) for the initial 30 days after sowing then they were kept at $40 \%$ drought condition throughout. All the new leaves that emerged and developed after 2 weeks of drought were investigated for the number of stomata and their size in the upper and lower epidermis.

Experiment 3: The plants were kept WW throughout the duration of experiment starting from emergence of plants to the fully maturity $(\sim 115$ DAS $)$. The $\mathrm{K}_{\mathrm{L}}$ and $\Psi_{\mathrm{L}}$ were measured and the differences were recorded over the season as the plant reached full maturity. The Pn, E and gs were measured regularly over the course of the experiment from the seedling to the fully mature plant stage to compare the changes in the physiological activities with the growing age of A. nuda plants.

A third set of the A nuda L. cultivars Ym and Dy7 were planted in pots in a growth room at $25^{\circ} \mathrm{C}, 14 / 10 \mathrm{~h}$ day/night, with supplemented light source and $\sim 60 \%$ relative humidity. The $\mathrm{K}_{\mathrm{L}}, \Psi_{\mathrm{L}}, \mathrm{Pn}, \mathrm{E}$ and gs were measured regularly from the seedling to mature plant stage to compare the changes in the physiological activities under field condition to rule out the effect of temperature and ambient humidity in the field conditions and serve as a control.

\section{Leaf water potential $\left(\Psi_{L}\right)$}

Leaf water potential $\left(\Psi_{\mathrm{L}}\right)$ was measured at 6 a.m. and midday at $12 \mathrm{pm}$ daily for the plants under different water treatments and control with a pressure bomb (PMS Instrument Company ${ }^{\odot}$ USA) with some modifications in the actual protocol (Boyer 1967).

\section{Hydraulic conductance of leaf $K_{L}$}

The leaf hydraulic conductivity $\mathrm{K}_{\mathrm{L}}$ of both cultivars was measured regularly by using a pressure chamber (PMS Instrument Company, Albany, OR, USA) by rehydration kinetics method (RKM) (Brodribb and Holbrook 2003). For this method two leaves that were placed on the same level near each other were cut before sunrise and were immediately stored in a moist dark zip plastic bag. The leaves were taken to the laboratory for measurement of initial leaf water potential $\left(\Psi_{\mathrm{L}}\right)$, for this purpose, the $\Psi$ of first leaf served as the $\Psi_{1}$ and the second leaf was immersed in distilled water for $60 \mathrm{~s}$ and then equilibrated in a dark moist bag for $10 \mathrm{~min}$. After that, the final leaf water potential was measured with a pressure chamber in the same way as described earlier for measurement of $\Psi_{\mathrm{L}}$. Leaf hydraulic conductance $\mathrm{K}_{\mathrm{L}}$ was calculated as the water flow rate inside the leaf by using the following formula by Brodribb and Holbrook 2003.

$$
\mathrm{K}_{\mathrm{L}}=\mathrm{C} \times \ln \left(\Psi_{1} / \Psi_{\mathrm{f}}\right) \mathrm{t}-1 \mathrm{LA}-1
$$

Where $C$ is the leaf capacitance, $\Psi_{1}$ is the initial leaf water potential, $\Psi_{\mathrm{f}}$ is the final leaf water potential, $\mathrm{t}$ represents the duration of rehydration, while LA stands for leaf area. Leaf area was measured with a scanner using ImageJ software. All the measurements were taken in five biological replicates.

\section{Leaf capacitance $C_{L}$}

Fresh shoots were cut at night and rehydrated in distilled water overnight for $\mathrm{C}_{\mathrm{L}}$ measurement. Initial leaf water potential $\left(\Psi_{\mathrm{L}}\right)$ was measured using a pressure chamber when the leaf was completely turgid and the initial weight (WW) was measured with an analytical balance; the leaf was then allowed to desiccate progressively at the bench top for next $12 \mathrm{~h}$. at regular intervals $\Psi_{\mathrm{L}}$ was measured and change in the 
leaf weight was also measured, until the leaf water potential did not decline any further. Leaf area (LA) was calculated with the help of a scanner and ImageJ software. Leaf dry weight (DW) was measured by drying the leaf for 48 to 72 h. in an oven at $80^{\circ} \mathrm{C}$ and then the leaf weight was recorded. The recorded data was used to construct the pressurevolume curves and the value of $\mathrm{C}$ was calculated as the slope of the PV curve by using the following equation (Blackman and Brodribb 2011),

$$
\mathrm{C}_{\mathrm{L}}=\delta \mathrm{RWC} / \delta \Psi_{1} \times(\mathrm{DW} / \mathrm{LA}) \times(\mathrm{WW} / \mathrm{DW}) / \mathrm{M}
$$

Where WW is the fresh leaf weight, RWC is the relative water content of the leaf measured as the difference in the weight of the turgid leaf and the oven-dried leaf, and $\mathrm{M}$ is the mass of water. The $\mathrm{C}_{\mathrm{L}}$ for both the cultivars was used for calculation of $\mathrm{K}_{\mathrm{L}}$. The measurements were repeated over five times and mean value was calculated.

\section{Physiological responses of leaf under drought}

The Pn, E and gs were measured using a LI-6400 portable photosynthesis system (LI-COR, Lincoln, Nebraska, USA). The environmental conditions settings for measurements of physiological activities were as follows; the $\mathrm{CO}_{2}$ level was $\sim 400 \mu \mathrm{mol} \mathrm{CO} \mathrm{Col}^{-1}$ air, the chamber photon flux density was set at $\sim 1000 \mu \mathrm{mol} \mathrm{m} \mathrm{m}^{-2}$, the airflow rate was $\sim 500$ $\mu \mathrm{mol} \mathrm{s}{ }^{-1}$, the vapor pressure deficit (VPD) was adjusted at approximately $2.0 \mathrm{kPa}$, and the temperature was adjusted at $25^{\circ} \mathrm{C}$. The youngest fully flattened leaf while still attached to the plant was secured inside the leaf chamber and allowed to adjust in the chamber light for 1-2 min. The readings were recorded when all the values became constant and did not fluctuate any further, the procedure was replicated and means were calculated.

\section{Stomatal density and stomatal size}

Slides were prepared with upper and lower leaf epidermis of A. nuda cultivars Dy7 and Ym and were examined under Zeiuss fluorescent microscope. A mature fully expanded leaf was used for preparation of slides for the samples from different water treatments and the control samples. The size and density of stomata were determined using the MOTIC software; the values were recorded and compared for both the cultivars. A one fully mature leaf from each plant was selected and fixed immediately in FAA (the ratio of $70 \%$ ethanol, to ethanoic acid, to formalin was, by volume, 18:1:1). The fixed leaves were then softened in $10 \%$ chromic acid solution, and the leaf epidermis was peeled and mounted on a glass slide the coverslip was placed carefully. Five randomly selected fields of view (3-5 mm2) were selected to take images under a Motic microscope (Motic BA200, China). Using an image analysis system (Motic Images Advanced 3.2), SD was recorded at $\times 100$ magnification. SL was taken as the length between the junctions of the guard cells at each end of the stoma. More than 30 stomata were randomly selected for SL measurement at $\times 100$ and $\times 400$ magnification.

\section{Statistical analysis}

The means and Standard Deviation were calculated for the different variables measured, such as $\Psi_{\mathrm{L}}, \mathrm{K}_{\mathrm{L}}, \mathrm{SD}$, SS Pn, E and gs for both the cultivars. The differences between the two cultivars and different treatments were analyzed by a two way ANOVA (Fisher 1921). Tukey's post hoc honestly significant difference (HSD) $(p<0.05)$ was applied to calculate the significant variance amongst different means for $\Psi_{\mathrm{L}}, \mathrm{K}_{\mathrm{L}}, \mathrm{SD}, \mathrm{SS} \mathrm{Pn}, \mathrm{E}$ and gs for both the cultivars and the different water treatments and control groups. The Pearson's correlation test was applied to investigate the correlation amongst $\Psi_{\mathrm{L}}, \mathrm{K}_{\mathrm{L}}, \mathrm{SD}, \mathrm{SS}, \mathrm{Pn}, \mathrm{E}$ and gs against each other and against age of the plant counted as the days after sowing (DAS). The statistical analysis was performed using GraphPad prism version 8.4.3.

\section{Result}

The A. nuda cultivars Ym and Dy7 showed a significant decline $p<0.05$ in their $\Psi_{\mathrm{L}}, \mathrm{k}_{\mathrm{L}} \mathrm{Pn}, \mathrm{E}$ and gs with the growing age of the plants that were kept well-watered throughout the course of experiments to rule out the possibility of decline in these physiological activities due to soil drying. The $\Psi_{\mathrm{L}}, \mathrm{K}_{\mathrm{L}}, \mathrm{Pn}, \mathrm{E}$ and gs showed a strong positive correlation between each other showing $\mathrm{r}$ values of $0.8-0.9$ with significant $p$ values ranging from $p<0.0001$ to $\mathrm{p}<0.00001$. The age of plant was strongly negatively correlated with all the physiological activities with an $r$ value of -0.9 .

\section{Decline in $\Psi_{L}$ and $K_{L}$ due to aging}

The plant age and cultivars both represented a significant effect on the loss of $\mathrm{K}_{\mathrm{L}}$ under normal growth conditions $p$ > 0.00001 . Due to plant aging, there was a $50 \%$ loss of $\mathrm{K}_{\mathrm{L}}$ in the Ym cultivar of $A$. nuda whereas; Dy7 plants exhibited a percent loss of hydraulic conductivity (PLC) of $28 \%$ only (Fig. 1). The results for growth room experiment were almost similar to the experiment in the field.

A. nuda plants were generally maintained below -1 MPa predawn (PD) $\Psi_{\mathrm{L}}$ throughout the duration of their life but the midday (MD) had a variation of $-1 \mathrm{MPa}$ to $-1.5 \mathrm{MPa}$ for Dy7 and Ym. The first two months (60 DAS) A. nuda plants maintained their predawn leaf water potentials to below -0.5 MPa for both Ym and Dy7 cultivars. The plants did not face any water stress but still the MD leaf water potential dropped to - $0.5 \mathrm{MPa}$ for the cultivar Dy7 and -0.7 $\mathrm{MPa}$ for $\mathrm{Ym}$. There existed variations for MD and PD leaf water potentials of both the cultivars for instance, Ym MD leaf water potential was declined to $-0.7 \mathrm{MPa}$ at the age of Dy7 67 DAS whereas the same value of MD leaf water potential was noted in Dy7 at the age of 82 DAS. The MD 
leaf water potential of -1 MPa was recorded for Ym plants at the age of 82 DAS whereas the same leaf water potential was recorded for Dy 7 at full maturity i.e. at the age of 110 DAS (Fig. 2).

\section{Loss of Evapotranspiration (E)}

Aven nuda L. plants generally showed a decline in the midday $\mathrm{E}$ in response to the plant aging $p>0.00001$. There was major decline in the midday $\mathrm{E}$ for the cultivar $\mathrm{Ym}$. The maximum $\mathrm{E}$ was $7.4 \mathrm{mmol} \mathrm{m} \mathrm{m}^{-2} \mathrm{~s}^{-1}$ and $8.2 \mathrm{mmol} \mathrm{m}^{-2} \mathrm{~s}^{-1}$ for Ym and Dy7 respectively. As the $A$. nuda plants grow older the amount of water transpired through the stomata decreased for both the cultivars. At full maturity of the plants, the E value was $3.8 \mathrm{mmol} \mathrm{m}^{-2} \mathrm{~s}^{-1}$ and $4.7 \mathrm{mmol} \mathrm{m}^{-2} \mathrm{~s}^{-1}$ for $\mathrm{Ym}$ and Dy7 respectively showing a decline of $49 \%$ and $43 \%$ respectively. At the age of two months 60 DAS the decline in midday $E$ was $43 \%$ with $E$ value of $4.7 \mathrm{mmol} \mathrm{m}^{-2}$ $\mathrm{s}^{-1}$ for $\mathrm{Ym}$ whereas, in the Dy7 plants of same age the decline in the midday evapotranspiration was only $23 \%$ with a value of $6.3 \mathrm{mmol} \mathrm{m}^{-2} \mathrm{~s}^{-1}$ (Fig. 3).

\section{Net photosynthetic rate $(\mathbf{P n})$}

The age and cultivars had a significant effect on the net photosynthetic rates of the plants $p>0.00001$. The $A$. nuda exhibited a decline in the Pn in different ages of the plant kept under well-watered (WW) condition. The decline was more prominent in the cultivar Yanmai than Dinyou7. The maximum Pn was $17.6 \mu \mathrm{mol} \mathrm{m} \mathrm{s}^{-2}$ and $18.4 \mu \mathrm{mol} \mathrm{m} \mathrm{s}^{-2}$ for the Ym and Dy7 plants respectively at the midday in the young seedlings of $\mathrm{Ym}$ and Dy7. AT the age of 2 months, i.e. 60 DAS the A. nuda plants showed a decline of $\sim 11 \%$ decline in the net photosynthetic rates for both the cultivars. At full maturity, the Pn declined to 60.7 and $51 \%$ for $\mathrm{Ym}$ and Dy7 respectively (Fig. 4).

\section{Loss of gaseous exchange through stomata (gs)}

Similar to other physiological activities gs was also reduced with the plant aging and in response to a transient drought in the A. nuda plants. Dy7 showed a decline of $28 \%$ whereas $32 \%$ decline was recorded for Ym (Fig. 5). The calculated $\mathrm{p}$ value was $p>0.0001$ both for the cultivars and for the age of plants representing a significant effect of these two factors on the stomatal conductance.

\section{Stomatal density and stomatal size}

The arrangement of stomata was zigzag and denser in Ym as compared with Dy7. The stomata of Ym were almost distributed uniformly in both upper and lower stomata having the same size, while the stomata of Dy7 showed a statistically significant variance in distribution, density and size in upper and lower epidermis under the effect of drought and in the control.

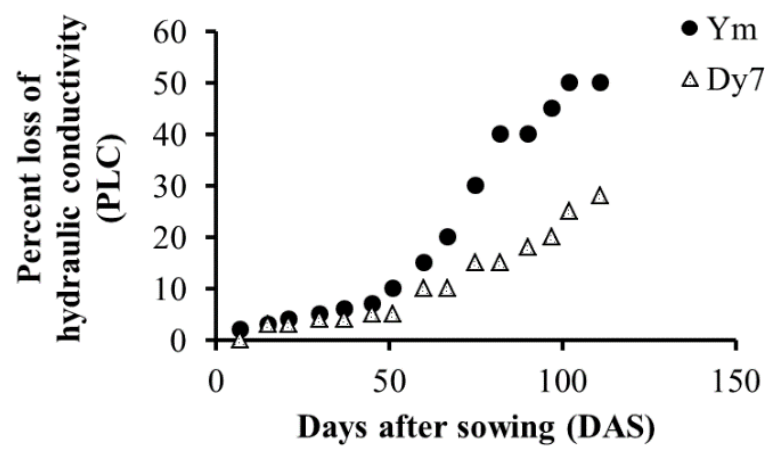

Fig. 1: The percent loss of leaf hydraulic conductance over the growing season in A. nuda cultivars Ym and Dy7. All the means (except for the second pair of means) represented in the figure showed significant variance tested by Tukey's post hoc HSD test $p>0.00001$

\section{Age of plants (DAS)}

$\begin{array}{llllllllllllll}7 & 15 & 21 & 30 & 37 & 45 & 51 & 60 & 67 & 75 & 82 & 90 & 97 & 102111\end{array}$

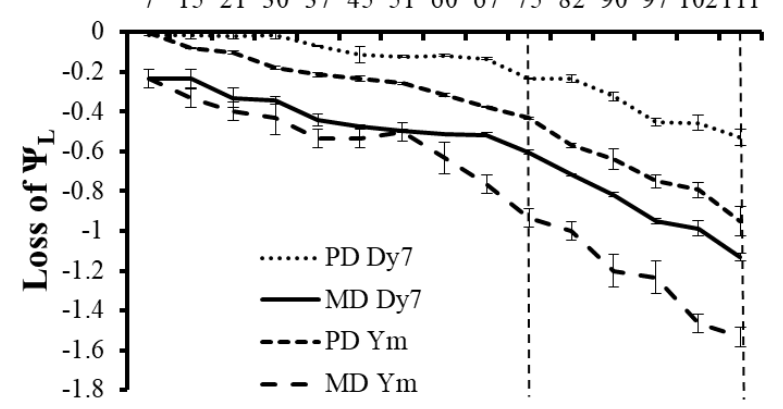

Fig. 2: The Midday loss of $\Psi_{\mathrm{L}}$ in $A$. nuda L. plants. The area between the dotted lines represent the $\Psi_{\mathrm{L}}$ at which most of the decline in $\mathrm{K}_{\mathrm{L}}, \mathrm{Pn}, \mathrm{E}$ and gs occurred and had a significant variance between the cultivars and the different ages of plant tested by Tukey's post hoc HSD test $p>0.00001$

*PD stands for Predawn leaf water potential

**MD stands for Midday leaf water potential

Ym leaves had higher number of stomata as compared to Dy7 both in the upper and lower leaf epidermis. The mean number of stomata in the upper epidermis of Dy7 was recorded as $1061.8 \pm 12.87 \mathrm{~mm}^{2}$ while in $\mathrm{Ym}$ it was much higher i.e. $1330.4 \pm 12.44 \mathrm{~mm}^{2}$ (Fig. 6a). The density of stomata in the lower epidermis was $1124.6 \pm 8.91 \mathrm{~mm}^{2}$ and $1425.8 \pm 19.64 \mathrm{~mm}^{2}$ in Dy 7 and Ym respectively (Fig. 6b) in the WS plants. The water stressed Dy7 showed $20 \%$ less number of stomata in the upper epidermis and $15 \%$ decrease in the density of lower epidermis stomata. However, Ym showed only $12 \%$ smaller number of stomata in upper epidermis and $9 \%$ smaller number of stomata in the lower epidermis.

Size of stomata in the upper epidermis was $14.24 \pm$ $0.82 \mu \mathrm{m}$ and $11.05 \pm 0.84$ in Dy $7 \mu \mathrm{m}$ and ym respectively (Fig. 7a) which clearly exhibits the larger stomatal size in the upper epidermis of Dy7. The stomata of lower epidermis in both the cultivars showed different sizes. It was $12.59 \pm$ $0.65 \mu \mathrm{m}$ and $10.83 \pm 0.58 \mu \mathrm{m}$ in Dy 7 and ym respectively 
(Fig. 7b). A reduction in the size of stomata was also noticed in the size of upper epidermis of Dy7 that showed a stomatal size of $11.1 \pm 0.51 \mu \mathrm{m}$. The stomata in the lower epidermis of Dy7 and both upper and lower epidermis of Ym showed negligible reduction in the size of stomata under the effect of drought.

Overall, there was a significant variant density and size of stomata in both the cultivars, indicating a significant role in better water management of the more recent cultivars as compared to the early one (Fig. 8).

\section{Recovery after drought}

The A. nuda showed significantly varied $(p<0.05)$ in their capability of recovery from a drought after re-watering.

Loss of $\mathbf{K}_{\mathbf{L}}$ under drought and recovery PLC: At $40 \%$ field water capacity the PLC for A. nuda was recorded as 80 and 39\% for Ym and Dy7 respectively. Maximum recovery of $\sim 88 \%$ was noted for plants of $\mathrm{Ym}$ and $\sim 96 \%$ was recorded for Dy7 at $100 \%$ FC. The A. nuda plants when rewatered to a $50 \% \mathrm{FC}$ for recovery from a transient drought of $40 \%$, the recovery of $\mathrm{K}_{\mathrm{L}}$ was 85 and $35 \%$ for Dy7 and Ym respectively (Table 1). The plants that were not rewatered did not show any recovery.

Midday $\Psi_{\mathbf{L}}(\mathrm{MPa})$ differences during drought and Post drought recovery: During an early ephemeral drought the $A$ nuda $\mathrm{L}$. cultivar $\mathrm{Ym}$ showed higher sensitivity to midday loss of $\Psi_{\mathrm{L}}$ than Dy7. The Dy7 plants recovered to -2.76 MPa the next morning for an early morning $\Psi_{\mathrm{L}}$ of $-2.25 \mathrm{MPa}$ the previous day, the noon $\Psi_{\mathrm{L}}$ was reduced to $-3 \mathrm{MPa}$ in Dy7 whereas, the same in the Ym plants was recovered to -2.92 MPa only. For an early morning $\Psi_{\mathrm{L}}$ of $-3 \mathrm{MPa}$ Ym plants exhibited a noon $\Psi_{\mathrm{L}}$ of $-3.5 \mathrm{MPa}$ which is the lethal $\Psi_{\mathrm{L}}$ for the ym leaves. The next morning the recovery of $\Psi_{\mathrm{L}}$ was to $-3.33 \mathrm{MPa}$ only while the Dy7 leaves, which can tolerate $\Psi_{\mathrm{L}}$ as low as -6 MPa exhibited a noon reduction from -3 MPa to $-3.79 \mathrm{MPa}$ while in the predawn next day the $\Psi_{\mathrm{L}}$ was recovered to $-3.26 \mathrm{MPa}$. The Dy7 leaves could tolerate lower $\Psi_{\mathrm{L}}$ of an early morning of $-5 \mathrm{MPa}$ which reduced to -5.72 $\mathrm{MPa}$ and recovered to $-5.61 \mathrm{MPa}$ (Table 2).

At $40 \%$ FC drought condition the midday $\Psi_{\mathrm{L}}$ was -1.5 MPa and -2.5 MPa for Dy7 and Ym respectively. A. nuda plants re-watered to $100 \%$ FC showed a recovery to -0.4 $\mathrm{MPa}$ and $-0.9 \mathrm{MPa}$ for Dy7 and $\mathrm{Ym}$ respectively. The plants that were rewatered to $50 \%$ FC showed recovery of a midday $\Psi_{\mathrm{L}}$ to $-1 \mathrm{MPa}$ and $-1.7 \mathrm{MPa}$ for Dy7 and $\mathrm{Ym}$ respectively (Table 1).

Loss of $\mathbf{E}$ under drought and post drought recovery: The A. nuda plant also lost midday transpiration at $40 \% \mathrm{FC}$. Yanmai showed a decline of $53 \%$ in the midday transpiration, under the same water stressed condition the Dingyou7 plants showed $47 \%$ decline in the midday transpiration.

The A. nuda plants showed a variation in the recovery of midday $\mathrm{E}$ from the drought under different watering schemes. At $100 \%$ FC the recovery for MD transpiration

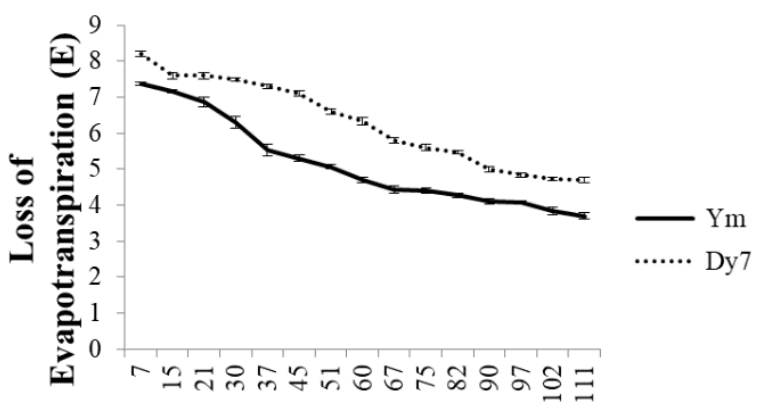

Age of plants (DAS)

Fig. 3: Loss of midday evapotranspiration $\left(E=m m o l ~ m^{-2} \mathrm{~s}^{-1}\right)$ in $A$. nuda plants under normal growth conditions, all the means differed significantly tested by post hoc test Tukey's HSD $p>0.00001$

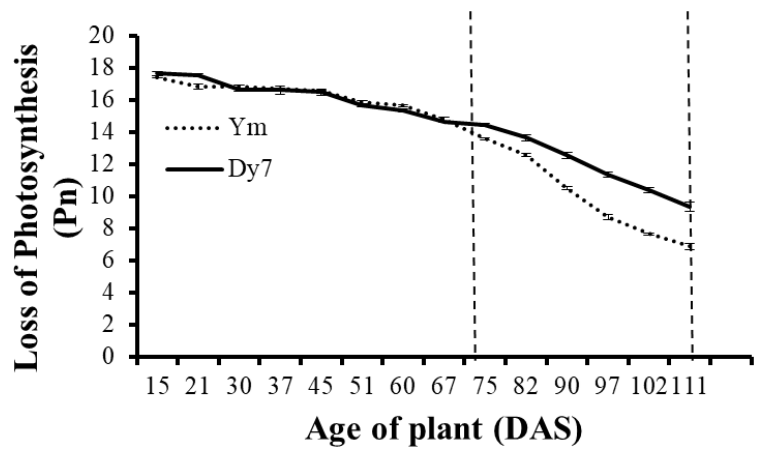

Fig. 4: Loss of midday net photosynthetic rates $\left(\mathrm{Pn}=\mu \mathrm{mol} \mathrm{m}{ }^{-2} \mathrm{~s}^{-1}\right)$ in Avena nuda L. plants with the aging of plant under well watered growth conditions, the area between the dotted lines represent the significant variation of $\mathrm{Pn}$ in the cultivars and the age Tukey's HSD test $\mathrm{p}>0.00001$

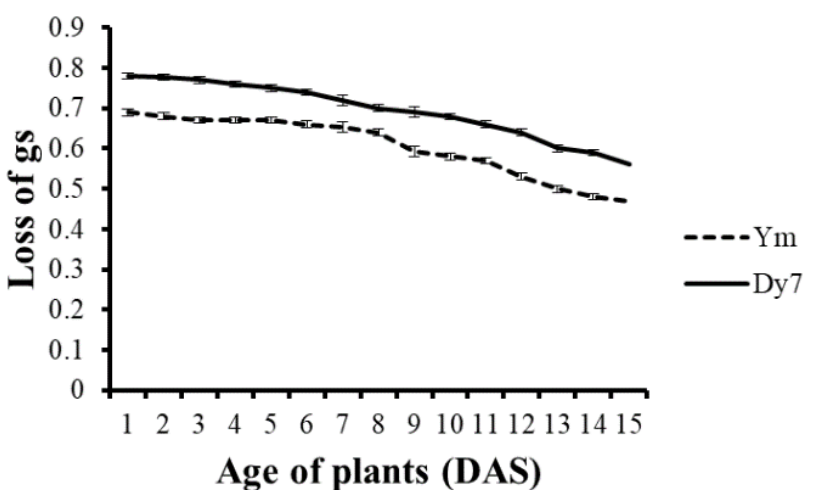

Fig. 5: Loss of gs $\left(\mathrm{mol} \mathrm{m}^{-2} \mathrm{~s}^{-1}\right)$ in A. nuda with plant aging under well-watered conditions. The different gs values calculated at different ages showed statistically significant effects of plant age on the gs the means differed significantly for both the cultivars and ages $p>0.00001$

rates were 7.1 and $5.4 \mathrm{mmol} \mathrm{m}^{-2} \mathrm{~s}^{-1}$ showing a recovery of 87 and $73 \%$ for Dy 7 and $\mathrm{Ym}$ respectively. The recovery under $50 \% \mathrm{FC}$ was $5.6 \mathrm{mmol} \mathrm{m}^{-2} \mathrm{~s}^{-1}$ and $4.1 \mathrm{mmol} \mathrm{m}^{-2} \mathrm{~s}^{-1}$ representing a recovery of 68 and 55\% for Dy7 and $\mathrm{Ym}$ respectively (Table 1$)$. 

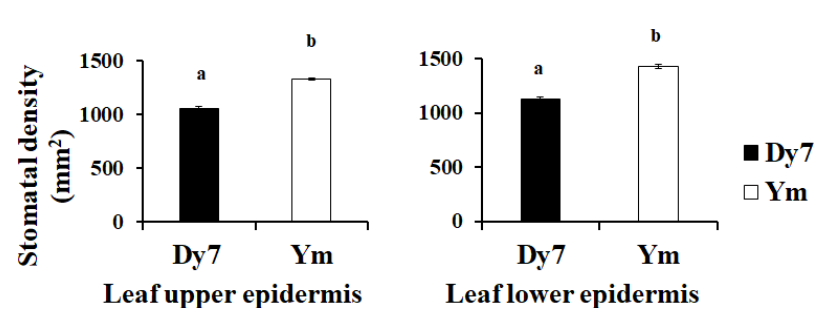

Fig. 6: (a) Stomatal Density of Dy7 and Ym in upper epidermis (b) The density of stomata in the lower epidermis of both the cultivars. The values are mean $(n=5)$. The different letters represent significant variance at $p<0.05$. The error bars exhibit range of standard deviation from the calculated mean
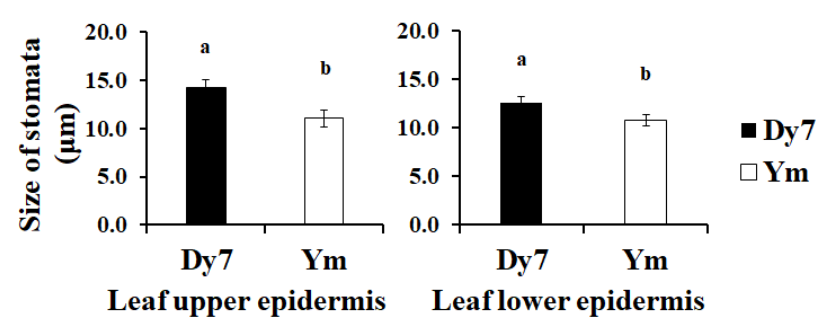

Fig. 7: (a) Size of Stomata in Upper and Epidermis of Dy7 and Ym, (mean \pm SD). (b) The size of stomata in Dy7 and Ym lower epidermis. (mean \pm SD mean). The different letters represent significant variance at $p<0.05$

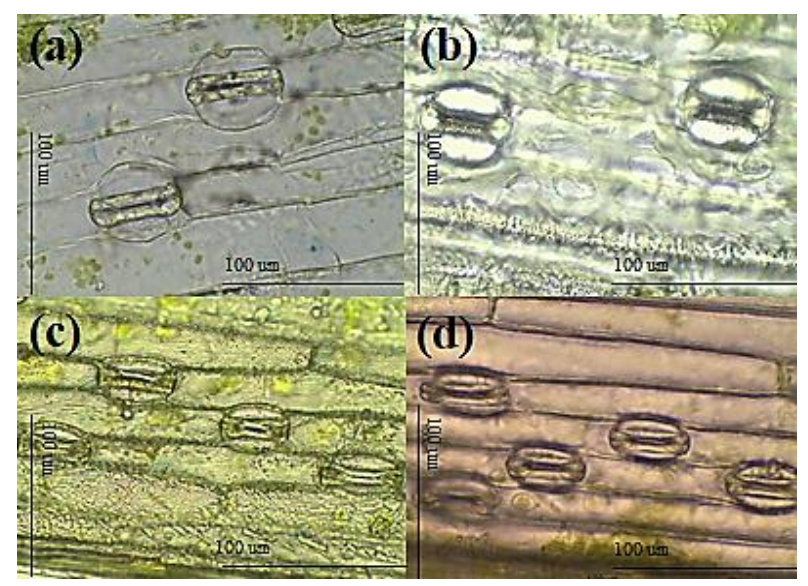

Fig. 8: (a) Dy7 lower epidermis (b) Dy7 upper epidermis (c) Ym lower epidermis (b) upper epidermis showing size and density of stomata in the epidermis

\section{Leaf gas exchange}

Recovery of net photosynthetic rate (Pn): The young plants of $A$. nuda plants also exhibited loss of Pn under a transient $40 \%$ FC drought condition. The decline in Pn was 43 and 56\% for Dy7 and Ym plants respectively.

After the transient drought the A. nuda that were recovered under a $100 \%$ FC showed a Pn recovery of 92 and $85 \%$ and under $50 \%$ FC, watering scheme it was 79 and $64 \%$ for Dy7 and Ym plants respectively. The plants with no watering did not recover their Pn instead further decrease was recorded in the Pn values (Table 1).

Post drought recovery of stomatal conductance (gs): Under a drought of $40 \%$ FC, the plants showed a loss of $\sim 58 \%$ for both the cultivars.

The plants showed a varied recovery from the transient drought. The recovery at $100 \%$ FC was 60 and $80 \%$ for $\mathrm{Ym}$ and Dy7 plants respectively. At 50\% FC, the plants showed a recovery of $\sim 53 \%$ for both the cultivars (Table 1 ). The plants kept under no watering condition could not recover from the drought condition and a further decline in the stomatal conductance was noticed for them until full loss of gs and death of plant.

\section{Discussion}

The present study investigated the intraspecific variations in the plants of Avena nuda L. The study comprised of two cultivars $\mathrm{Ym}$ and Dy7 with contrasting resistance to soil water status (Wang et al. 2017). These plants exhibited a variation of -1.5 MPa to -2.5 MPa in their midday leaf water potential for Dy7 and Ym respectively, at 40\% FC. The cultivars not only showed a variation in their hydraulic response towards a transient drought condition but also in their ability to recover from drought condition in different watering patterns. The effect of age of plant varied on the different physiological activities of $A$. nuda cultivars.

The plants become accustomed to dry soil and their capability to maintain their productivity under scarce water conditions is recognized as an evolutionary process, generally this is attributed to the woody plants but herbaceous plants have also been reported to adjust to the dryer environments (Lens et al. 2016). The A. nuda cultivars showed a significant variation in their resistance to xylem embolism under normal watering conditions where the environmental conditions were constant throughout our experiments. These variations in the resistance of a herbaceous plant species are suggested to be dependent on the age of plant rather than the environmental conditions (Dória et al. 2018). The cultivar Dy7 showed greater resistance to midday $\Psi_{\mathrm{L}}$ and $\mathrm{K}_{\mathrm{L}}$ decline in response to plant aging than $\mathrm{Ym}$ that revealed greater dependence of plant's hydraulic traits on the plant age, the cultivar Ym showed a significant decline in $\Psi_{\mathrm{L}}$ and $\mathrm{K}_{\mathrm{L}}$ with growing age of the plants. In agreement with our findings for $A$. nuda, Lovisolo et al. (2010) also reported the variation in the midday leaf water potential due to differences between different verities of grapevines Vitis vinifera L. In contrast, fluctuations in the hydraulic behaviors of the same variety has been also reported (Charrier et al. 2018) that may arise due to interaction of plants with different environmental conditions, therefore it is not universal for a given plant variety (Feng et al. 2019). This variation might be driven by many factors that may be structural or age of plant. Large intraspecific variation in xylem resistance has also been shown to result in heterogeneous mortality across the canopy in a tree species exposed to drought, with 
Table 1: Loss of $\Psi_{\mathrm{L}}, \mathrm{K}_{\mathrm{L}}$, gs, E and Pn under drought and recovery after re-watering to $50 \% \mathrm{FC}$ and $100 \%$ FC. The different means for all the parameters represented differed significantly $p<0.05 . \Psi_{\mathrm{L}}=$ Leaf water potential (MPa), $\mathrm{K}_{\mathrm{L}}=$ PLC percent loss of leaf hydraulic conductance (\%), gs stomatal conductance $\mathrm{mol} \mathrm{m}^{-2} \mathrm{~s}^{-1}, \mathrm{E}=$ evapotranspiration $\left(\mathrm{mmol} \mathrm{m} \mathrm{s}^{-1}\right), \mathrm{Pn}=$ net photosynthesis rate $\left(\mu \mathrm{mol} \mathrm{m} \mathrm{m}^{-2} \mathrm{~s}^{-1}\right)$

\begin{tabular}{|c|c|c|c|c|c|}
\hline Genotype & $\Psi_{\mathrm{L}}$ & $\mathrm{K}_{\mathrm{L}}$ & gs & $\mathrm{E}$ & Pn \\
\hline \multicolumn{6}{|c|}{ Well- watered Control 100\% FC } \\
\hline Ym & -0.002 & 100 & 0.71 & 7.90 & 17.60 \\
\hline Dy7 & -0.002 & 100 & 0.78 & 8.03 & 18.20 \\
\hline \multicolumn{6}{|c|}{ Transient drought condition $40 \%$ FC } \\
\hline Ym & -2.5 & 20 & 0.30 & 3.56 & 9.93 \\
\hline Dy7 & -1.5 & 59 & 0.32 & 4.40 & 12.30 \\
\hline \multicolumn{6}{|c|}{ Recovery after re-watering to $100 \% \mathrm{FC}$} \\
\hline Ym & -1.0 & 88 & 0.47 & 5.46 & 15.00 \\
\hline Dy7 & -0.4 & 96 & 0.60 & 7.16 & 16.90 \\
\hline \multicolumn{6}{|c|}{ Recovery after re-watering to $50 \% \mathrm{FC}$} \\
\hline Ym & -1.8 & 35 & 0.36 & 4.10 & 11.30 \\
\hline Dy7 & -0.7 & 85 & 0.42 & 5.60 & 14.63 \\
\hline
\end{tabular}

Table 2: Midday $\Psi_{\mathrm{L}}$ sensitivity of Dy7 and Ym plants, during vegetative growth period

\begin{tabular}{|c|c|c|c|c|}
\hline Time & $5-6 \mathrm{am}$ & $12-1 \mathrm{pm}$ & $5-6 \mathrm{am}$ & $12-1 \mathrm{pm}$ \\
\hline Genotype & Dy7 & Dy7 & $\mathrm{Ym}$ & Ym \\
\hline 1 & 0.021 & 0.31 & 0.0023 & 0.323 \\
\hline 5 & 0.5 & 0.89 & 0.5 & 1.42 \\
\hline 7 & 1.0 & 1.87 & 1.0 & 1.98 \\
\hline 9 & 1.5 & 2.04 & 1.5 & 2.32 \\
\hline 10 & 2.0 & 2.78 & 2.0 & 2.98 \\
\hline 11 & 2.5 & 3.04 & 2.5 & 3 \\
\hline 12 & 3.1 & 3.79 & 3 & 3.5 \\
\hline 13 & 3.5 & 4.09 & - & - \\
\hline 14 & 4.0 & 4.59 & - & - \\
\hline 15 & 4.5 & 5.23 & - & - \\
\hline 16 & 5.0 & 5.72 & - & - \\
\hline 17 & 5.5 & 6 & - & - \\
\hline
\end{tabular}

considerable impacts on plant photosynthesis even after rehydration (Cardoso et al. 2020).

Plants need carbohydrates and ATP's generated by their breakdown for their survival, without loss of water through stomata the plants cannot capture carbon for assimilation. This is a sort of trade between the plant and environment in which, plants give water and take carbon to prepare food. When plants transpire more water the hydraulic conductance increased in turn, the net photosynthetic rate also increased (Sack and Scoffoni 2013). In line with our results, Locke and Ort (2014) have reported that the photosynthetic activity is dependent on the age of plant showing a decrease in photosynthesis with the growing age of plant. Our results for the A nuda L. plant species showed a strongly negative correlation between the age of plant and the assimilation rates (Fig. 4). The gs in plants depends on the amount of soil water. The loss of $\mathrm{K}_{\mathrm{L}}$ and gs in $A$. nuda were positively correlated with each other for both the cultivars. The stomatal conductance in $A$. nuda cultivars was affected by the amount of water in soil and age of plant for both the cultivars whereas, inter-varietal differences also existed between the selected cultivars as Dy7 showed lesser decline in stomatal conductance in comparison with the cultivar Ym. McAdam at al. (2016) have also reported reduction in the gs of plants due to the loss of leaf turgidity in response to dryer soil. The stomatal density and size may be one of the reasons for better water use efficiency by the $A$. nuda cultivar Dy7 (data not shown here) because the number of stomata was lower in Dy7 than $\mathrm{Ym}$ in both the upper and lower leaf epidermis. Fewer numbers of stomata are considered an important evolutionary attribute of plants. Wheat cultivars have been reported to show similar adaptation to dryer environment with lower number of stomata in the leaf epidermis (Dunn et al. 2019). The cultivar Dy7 possessed larger stomata size for water stressed and control plants in comparison with the Ym plants. The pattern of stomata on the leaf epidermis is determined genetically, Dy7 plants showed less number of stomata in the present study (Fig. 8a, b). This attribute could be very useful for plant breeding. Bread wheat has been shown to genetically control the development of stomata in their leaf surfaces and exploiting these genes can be useful for better adaptation of cereal crops in the scenario of climate change with dryer and hotter environment prevailing in most parts of the world (Dunn et al. 2019). The size and number of stomata in the present study showed a strong negative correlation, Dy7 showed fewer numbers of stomata at both the leaf surfaces in general but the upper epidermis of Dy7 showed the least stomatal density. Shahinnia et al. (2016) have reported the negative correlation between the stomatal size and density in wheat Triticum aestivum L., representing the lower number and 
larger size of stomata as an important evolutionary adaptation against dryer environmental conditions.

Besides the aforementioned factors, the stomatal regulation might also controlled by other factors like ABA hormone signaling and its amount in the leaf and other tissue (McAdam and Brodribb 2015). Creek at al. (2019) have reported that a decline in evapotranspiration of woody angiosperms can actually preserve plants from loss of hydraulic conductance for both the stem and leaf. The $A$. nuda showed some level of recovery of leaf water potential from drought by partial re-watering to a field water capacity of $50 \%$ and maximum recovery after re-watering to $100 \%$ FC showing the fatal leaf water potential or deadly drought level was much lower for this plant species. The dynamics of leaf hydraulic conductance and fatal leaf water potential might be different for different plant species. Interspecific differences existed between the different plant species that might possibly be affected by many factors such as, the level and duration of drought, age of plant, post size, the experimental layout (Poorter et al. 2012) and the environmental conditions. The woody plants species behaved differently for upper and lower parts of the plant under a drought stress, the level of drought could be mortal for the leaves occurring near the tip of the plants, but lower leaves, stem and roots may still survive. This seemed an adaptive characteristic of plant species to shed some of the leaves for the survival of other parts of the plant, a strategy to minimize the burden on the plant so the reserved food could be utilized for the plant survival (Griffiths et al. 2014). These findings suggested that although the leaves might not recover from a severe drought but this did not mean death of the whole plant.

The leaf hydraulic conductance depicts the resistance of movement of water from the different pathways inside the plant until it move out of the plant through transpiration. Two main resistances faced by this movement of water through plant tissue consist of the pathway inside the xylem and the resistance of plant tissue outside the xylem (Buckley et al. 2017). The pathways inside xylem and the tissue outside xylem exert different magnitude of resistance upon the water movement from roots to the leaves (Trifilò et al. 2016). These two pathways determine the xylem embolism and resistance of different plant species to it, because these exert different scale of resistance for diverse plant species. The xylem embolism in $A$. nuda in the present study had a significant negative correlation with leaf water potential, stomatal conductance, and photosynthesis transpiration rates and resistance to embolism. Ogasa et al. (2013) have reported a negative correlation between the recovery of xylem embolism from a moderate drought stress and the resistance to xylem embolism in seven tree species. In agreement with the findings of Skelton et al. (2017) for eight plant species at canopy level and underneath vegetation in an evergreen forest, the $A$. nuda plants in the present study showed recovery of leaf hydraulic and physiological traits under a severe drought of $40 \%$ field water capacity. Representing the ability of this species to recover from relatively severe drought conditions, its hydraulic system is preserved and a complete hydraulic failure requires extreme drought for this plant species. The hydraulic and physiological performance, of two cultivars varied for different plant parameters in the present studies.

\section{Conclusion}

Avena nuda cultivars showed resistance against drought with better performance of the cultivar Dy7 in comparison with Ym. The cultivar Dy7 could maintain better hydraulic and physiological activities than Ym under the effect of both drought and age. The post drought recovery under different watering patterns was also better in Dy7 than the Ym. The cultivar Dy7 displayed a lower number while a bigger size of stomata on both the leaf surfaces but more reduced number of stomata in the upper surface of leaf, which may be an important factor in controlling the plant hydraulic efficiency, and better yield under drought conditions.

\section{Acknowledgements}

The funding provided by Sardar Bahadur Khan Women's University Quetta, Balochistan, Pakistan, under Higher Education Commission's (FDP) Split PhD fellowship awarded to Ms. Huma Batool is highly acknowledged. The equipment and lab supplies were kindly provided by Professor Dr. Xiangwen Fang's Lab (State Key Laboratory of Grassland Agro-ecosystems, School of Life Sciences) Lanzhou University, Gansu, China.

\section{Author Contributions}

TY and SF designed and supervised the study. HB performed all the experiments and statistical analysis. All the authors contributed in writing and editing of the manuscript.

\section{References}

Bertolino LT, RS Caine, JE Gray (2019). Impact of stomatal density and morphology on water-use efficiency in a changing world. Front Plant Sci 10; Article 225

Blackman CJ, TJ Brodribb (2011). Two measures of leaf capacitance: insights into the water transport pathway and hydraulic conductance in leaves. Funct Plant Biol 38:118-126

Boyer JS (1967). Leaf water potentials measured with a pressure chamber. Plant Physiol 42:133-337

Brodribb TJ, NM Holbrook (2003). Stomatal closure during leaf dehydration, correlation with other leaf physiological traits. Plant Physiol 132:2166-2173

Buckley TN, GP John, C Scoffoni, L Sack (2017). The sites of evaporation within leaves. Plant Physiol 173:1763-1782

Caine RS, X Yin, J Sloan, EL Harrison, U Mohammed, T Fulton, AK Biswal, J Dionora, CC Chater, RA Coe, A Bandyopadhyay, EH Murchie, R Swarup, WP Quick, JE Gray (2019). Rice with reduced stomatal density conserves water and has improved drought tolerance under future climate conditions. New Phytol 221:371-384 
Cardoso AA, TJ Brodribb, CJ Lucani, FM DaMatta, SAM McAdam (2018). Coordinated plasticity maintains hydraulic safety in sunflower leaves. Plant Cell Environ 41:2567-2576

Cardoso AA, TA Batz, SAM McAdam (2020). Xylem embolism resistance determines leaf mortality during drought in Persea americana. Plant Physiol 182:547-554

Charrier G, S Delzon, JC Domec, L Zhang, CEL Delmas, I Merlin, D Corso, A King, H Ojeda, N Ollat, JA Prieto, T Scholach, P Skinner, C Leeuwen, GA Gambetta (2018). Drought will not leave your glass empty: low risk of hydraulic failure revealed by long-term drought observations in world's top wine regions. Sci Adv 4; Article eaao6969

Creek D, LJ Lamarque, JM Torres-Ruiz, C Parise, R Burlett, DT Tissue, S Delzon (2019). Xylem embolism in leaves does not occur with open stomata: evidence from direct observations using the optical visualization technique. J Exp Bot 71:1151-1159

Dória LC, DS Podadera, DM Arco, T Chauvin, E Smets, S Delzon, F Lens (2018). Insular woody daisies (Argyranthemum, Asteraceae) are more resistant to drought-induced hydraulic failure than their herbaceous relatives. Funct Ecol 32:1467-1478

Dunn J, L Hunt, M Afsharinafar, M Meselmani, A Mitchell, R Howells, E Wallington, AJ Fleming, JA Gray (2019). Reduced stomatal density in bread wheat leads to increased water-use efficiency. $J$ Exp Bot 70:4737-4748

Feng X, DD Ackerly, TE Dawson, S Manzoni, B McLaughlin, RP Skelton, G Vico, AP Weitz, SE Thompson (2019). Beyond isohydricity: The role of environmental variability in determining plant drought responses. Plant Cell Environ 42:1104-1111

Fisher RA (1921). Studies in Crop Variation. I. An examination of the yield of dressed grain from Broadbalk. J Agric Sci 11:107-135

Fisher RA (1971) (1935). The Design of Experiments, $\left(9^{\text {th }}\right.$ edn.). Macmillan, New York, USA

Griffiths CA, DF Gaff, AD Neale (2014). Drying without senescence in resurrection plants. Front Plant Sci 5; Article 36

Gu L, C Jie, Y Jiabo, C Sylvia, HW Sullivan, G Shenglian, L Zhang, J Kim (2020). Projected increases in magnitude and socioeconomic exposure of global droughts in and warmer climates. Hydrol Earth Syst Sci 241:451-472

Hughes J, C Hepworth, C Dutton, JA Dunn, L Hunt, J Stephens, R Waugh, DD Cameron, JE Gray (2017). Reducing stomatal density in barley improves drought tolerance without impacting on yield. Plant Physiol 174:776-787

Lawson T, S Vialet-Chabrand (2019). Speedy stomata, photosynthesis, and plant water use efficiency. New Phytol 221:93-98

Lens F, C Picon-Cochard, C Delmas, C Signarbieux, A Buttler, H Cochard, S Jansen, T Chauvin, LC Doria, M Arco, S Delzon (2016). Herbaceous angiosperms are not more vulnerable to drought-induced embolism than angiosperm trees. Plant Physiol 172:661-667

Liu Y, L Qin, L Han, Y Xiang, D Zhao (2015). Overexpression of maize SDD1 (ZmSDD1) improves drought resistance in Zea mays L. by reducing stomatal density. Plant Cell Tiss Org Cult 122:147-159

Locke AM, DR Ort (2014). Leaf hydraulic conductance declines in coordination with photosynthesis, transpiration and leaf water status as soybean leaves age regardless of soil moisture. J Exp Bot 65:6617-6627

Lovisolo C, I Perrone, A Carra, A Ferrandino, J Flexas, H Medrano, A Schubert (2010). Drought-induced changes in development and function of grapevine (Vitis spp.) organs and in their hydraulic and non-hydraulic interactions at the whole-plant level: A physiological and molecular update. Funct Plant Biol 37:98-116

Mauri R, AA Cardoso, MM da Silva, LA Oliveira, RT Avila, SCV Martins, FM DaMatta (2020). Leaf hydraulic properties are decoupled from leaf area across coffee species. Trees 34:1507-1514

McAdam SAM, TJ Brodribb (2015) Hormonal dynamics contributes to divergence in seasonal stomatal behavior in a monsoonal plant community. Plant Cell Environ 38:423-432
McAdam SA, FC Sussmilch, TJ Brodribb (2016). Stomatal responses to vapor pressure deficit are regulated by high speed gene expression in angiosperms. Plant Cell Environ 39:485-491

Meinzer FC, DR Woodruff, DE Marias, DD Smith, KA McCulloh, AR Howard, AL Magedman (2016). Mapping 'hydroscapes' along the iso- to anisohydric continuum of stomatal regulation of plant water status. Ecol Lett 19:1343-1352

Mendez-Alonzo R, F Pineda-Garcia, H Paz, JA Rosell, ME Olson (2013). Leaf phenology is associated with soil water availability and xylem traits in a tropical dry forest. Trees 27:745-754

Morales-Navarro S, R Pérez-Díaz, A Ortega, A de Marcos, M Mena, C Fenoll, E González-Villanueva, S Lara (2018). Overexpression of a SDD1-like gene from wild tomato decreases stomatal density and enhances dehydration avoidance in Arabidopsis and cultivated tomato. Front Plant Sci 9; Article 940

Nardini A, M Battistuzzo, M, T Savi (2013). Shoot desiccation and hydraulic failure in temperate woody angiosperms during an extreme summer drought. New Phytol 200:322-329

Ogasa M, NH Miki, Y Murakami, K Yoshikawa (2013). Recovery performance in xylem hydraulic conductivity is correlated with cavitation resistance for temperate deciduous tree species. Tree Physiol 33:335-344

Ogbaga C, P Stepien, G Johnson (2014). Sorghum (Sorghum bicolor) varieties adopt strongly contrasting strategies in response to drought. Physiol Plantarum 152:389-401

Poorter H, J Bühler, D van Dusschoten, J Climent, JA Postma (2012). Pot size matters: a meta-analysis of the effects of rooting volume on plant growth. Funct Plant Biol 39:839-850

Rodriguez-Dominguez CM, MR Carins-Murphy, C Lucani, TJ Brodribb (2018). Mapping xylem failure in disparate organs of whole plants reveals extreme resistance in olive roots. New Phytol 218:1025-1035

Rosas T, J Martínez-Vilalta, M Mencuccini, H Cochard, J Barba, S Saura-Mas (2019). Adjustments and coordination of hydraulic, leaf and stem traits along a water availability gradient. New Phytol 223:632-646

Sack L, C Scoffoni (2013). Leaf venation: structure, function, development, evolution, ecology and applications in the past, present and future. New Phytol 198:983-1000

Shahinnia F, JL Roy, B Laborde, B Sznajder, P Kalambettu, S Mahjourimajd, J Tilbrook, D Fleury (2016). Genetic association of stomatal traits and yield in wheat grown in low rainfall environments. BMC Plant Biol 16; Article 150

Skelton RP, TJ Brodribb, SAM McAdam, PJ Mitchell (2017). Gas exchange recovery following natural drought is rapid unless limited by loss of leaf hydraulic conductance: evidence from an evergreen woodland. New Phytol 215:1399-1412

Trifilò P, F Raimondo, T Savi, MA Gullo, A Nardini (2016). The contribution of vascular and extra-vascular water pathways to drought-induced decline of leaf hydraulic conductance. $J$ Exp Bot 67:5029-5039

Venturas MD, JS Sperry, UG Hacke (2017). Plant xylem hydraulics: what we understand, current research, and future challenges. J Integr Plant Biol 59:356-389

Wang T, TL Du, H Jin, NC Turner, B Wang, C Zhang, T Cui, FM Li (2017). Recently-released genotypes of naked oat (Avena nuda L.) out-yield early releases under water-limited conditions by greater reproductive allocation and desiccation tolerance. Field Crops Res 204:169-179

Zhang Y, C Carmesin, L Kaack, MM Klepsch, M Kotowska, T Matei, HJ Schenk, M Weber, P Walther, V Schmidt, S Jansen (2020). High porosity with tiny pore constrictions and unbending pathways characterise the 3D structure of intervessel pit membranes in angiosperm xylem. Plant Cell Environ 43:116-130

Zsögön A, AC Negrini, LEP Peres, HT Nguyen, MC Ball (2015). A mutation that eliminates bundle sheath extensions reduces leaf hydraulic conductance, stomatal conductance and assimilation rates in tomato (Solanum lycopersicum). New Phytol 205:618-626 